OPEN ACCESS

Edited by:

Wen Zeng,

Chongqing University, China

Reviewed by:

Hongfu Mi,

Chongqing University of Science and

Technology, China

Jie Zhang,

Chongqing University, China

Shenghua Zou,

Hunan University of Science and

Technology, China

*Correspondence:

Liang $\mathrm{Ge}$

cgroad@swpu.edu.cn

Specialty section: This article was submitted to

Smart Materials,

a section of the journal

Frontiers in Materials

Received: 29 July 2020

Accepted: 03 September 2020

Published: 30 September 2020

Citation:

Xiao $G$, Weng $H$, Ge $L$ and Huang $Q$ (2020) Application Status of Carbon Nanotubes in Fire Detection Sensors.

Front. Mater. 7:588521.

doi: $10.3389 /$ fmats.2020.588521

\section{Application Status of Carbon Nanotubes in Fire Detection Sensors}

\author{
Guoqing Xiao ${ }^{1,2,3}$, Hengxiang Weng ${ }^{1,2}$, Liang Ge ${ }^{1,2 *}$ and Qi Huang ${ }^{1,2}$ \\ ${ }^{1}$ Electrical and Mechanical Engineering Department, Southwest Petroleum University, Chengdu, China, ${ }^{2}$ Oil and Gas Fire \\ Protection Key Laboratory of Sichuan Province, Chengdu, China, ${ }^{3}$ Chemistry and Chemical Engineering Department, Southwest \\ Petroleum University, Chengdu, China
}

With the rapid development of the city, all kinds of high-rise buildings, large shopping malls and entertainment places have been built one after another. There are some hidden dangers of fire accidents. Effective prevention and monitoring of fire is the focus of fire prevention and control field. As the information source of fire prevention and control, the preparation of fire detection sensor with high sensitivity and short response time is of great significance for fire prevention and monitoring. At present, the commonly used fire detection sensors mainly include $\mathrm{CO}$ sensor, temperature sensor and flame sensor. The sensors detect the characteristic parameters in the fire environment and converts non-electric signals such as gas, temperature, and flame light into electric signals to achieve the purpose of fire warning. With the development of material technology in recent years, especially the development of Carbon Nanotube (CNT) technology, a new fire detection sensor represented by CNT materials has emerged. In this paper, the research progress of CNTs in fire detection sensors is reviewed. The applications of CNTs in CO detection, flame light detection and temperature detection are discussed in detail. Finally, the development trend of fire detection sensors based on CNTs is proposed, and the development direction of fire detection sensors in the Internet of things is prospected.

Keywords: carbon nanotubes, fire detection sensors, internet of things, application status, development trend

\section{INTRODUCTION}

The Internet of things was first proposed by Kevin Ashton in 1999 (Cardenas et al., 2020), then it was widely used in various fields. The core of the Internet of things is sensor, which can detect the changes of various physical and chemical quantities in the environment, convert these changes into electrical signals, and transmit them to various platforms for information sharing through wireless transmission. The essential requirement of internet of things (IoT) is that sensors and devices can operate for a long time without excessive offset or degradation (Gaur et al., 2019). Therefore, the key factor to promote the development of IoT in the future is to develop low-power and low-cost electronic sensors (Marinov, 2015). Nowadays, a variety of sensors have been developed for the Internet of things, such as temperature sensor (Chad et al., 2013), gas sensor (Sharma et al., 2014; Ge et al., 2019), pressure sensor (Takei et al., 2014), photoelectric sensor, etc. Now, with the continuous development of the Internet of things, it has been widely used in medical, public utilities, manufacturing, transportation, safety prevention and other fields (Sundmaeker et al., 2010). Especially in the safety prevention, the monitoring of the Internet of things plays a crucial role in preventing accidents. In recent years, accidents occur frequently in various places, of which fire accident is one of the disasters with the highest frequency at present. Using the Internet of Things to monitor fires has become a hot spot. The main causes of fire can be divided into smoldering fire and 
A

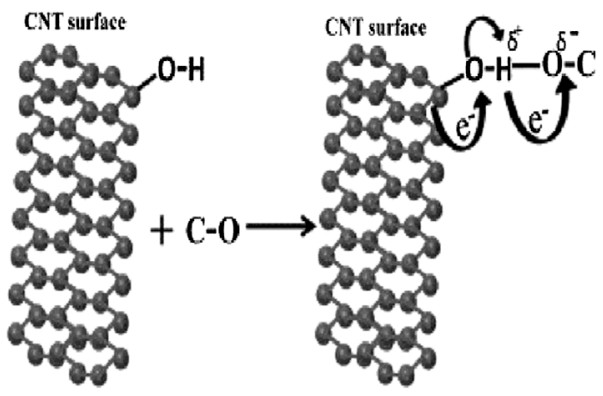

C

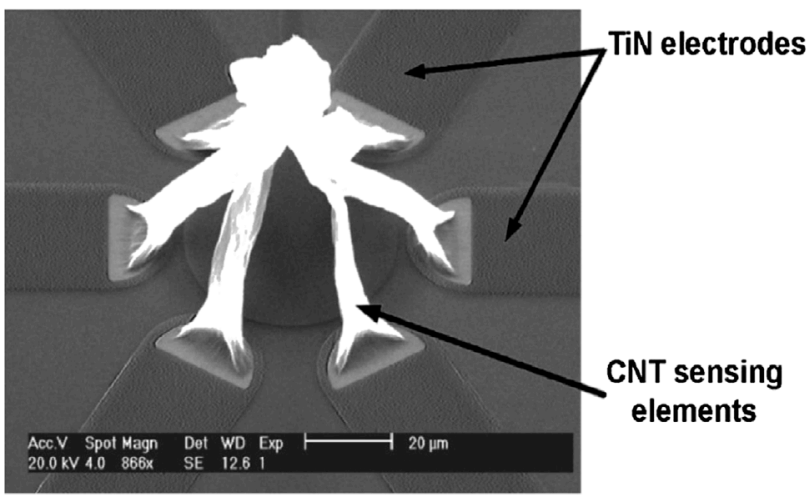

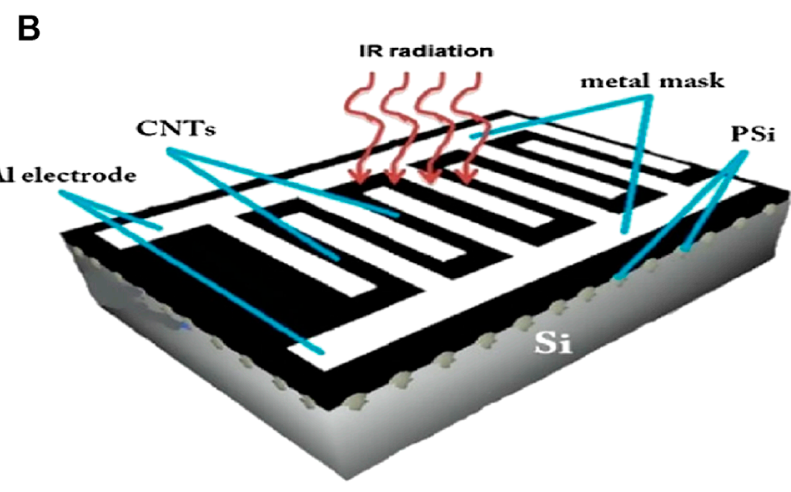

D

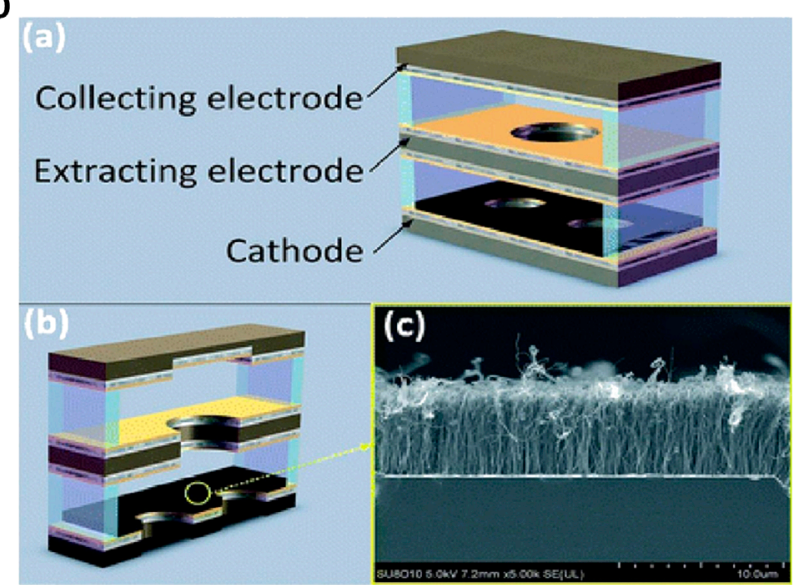

FIGURE 1 | (A) Adsorption of CO gas molecule on the carbon nanotubes (CNTs) functionalized with hydroxyl group. (B) Schematic diagram of the CNTs infrared photoconductive detector. (C) SEM images of the CNT based temperature sensor. (D) (a) The triple-electrode CNT-based sensor, (b) sectional view of the sensor, and (c) FE-SEM image of CNT film. Published by the Royal Society of Chemistry.

open fire. For the fire caused by smoldering fire, the concentration of smoke and co increased significantly in the early stage, and decreased significantly in the later stage; when the fire was caused by open fire, the $\mathrm{CO}$ concentration increased significantly in the early stage, but the smoke concentration decreased significantly, and the flame produced light radiation, and the smoke concentration increased rapidly in the later stage (Ding et al., 2018). Gas is one of the early characteristics of fire. The main gases used to detect fire include $\mathrm{CO}, \mathrm{CO}_{2}, \mathrm{NOx}$, methane, $\mathrm{H}_{2}$, $\mathrm{H}_{2} \mathrm{O}$, amine $\left(-\mathrm{NH}_{2}\right)$ (Xue et al., 2005; Wasisto et al., 2014). When a fire occurs, the temperature rises significantly, and the change of temperature can be detected by temperature sensor; the photoelectric detection for fire warning generates radiation light through flame combustion, and the sensor responds to the detection of light to detect the fire (Kwangjae et al., 2017). At present, gas sensors, temperature sensors and flame sensors are widely used in fire early warning system (Bogue, 2013; Fonollosa et al., 2018).

With the development of science and technology, more and more researchers study the preparation materials of sensors. Carbon nanotubes (CNTs) are one of the most popular electronic materials, which can improve the accuracy and response speed of sensors, thus promoting the development of IoT sensors (Chen et al., 2016). In
1991, Iijima first discovered CNTs, and then began to carry out a large number of studies on this material around the world (Iijima, 1991). It was found that CNTs have good electrical, physical, chemical and mechanical properties, for example, CNTs have good chemical stability, high carrier mobility, flexibility, etc., which greatly improve the performance of the sensor (Barcarolle et al., 2013). CNTs are hollow structures composed of graphene sheets. According to the number of graphene layers, CNTs are divided into single-walled CNTs (SWCNTs) and multi-walled CNTs (MWCNTs). MWCNTs are formed by crimping graphene (Wang et al., 2018); according to the spiral shape of graphene sheets, CNTs can be divided into two types (asymmetric type) and chiral type (symmetric type) (Tang, 2019). CNTs can be synthesized by a variety of methods, such as arc discharge (Iijima, 1991), laser ablation (Guo et al., 1995), chemical vapor deposition (JoseYacaman et al., 1993). At present, arc discharge has become the most widely used synthesis technology, which can produce SWCNTs and MWCNTs at the same time. Chemical vapor deposition is a common method for commercial production of CNTs. Among the three common methods, laser ablation has the highest cost, arc discharge has the lowest benefit, and chemical vapor deposition is the most effective method for commercial production of CNTs. In addition to $\mathrm{CNT}$ materials, CNT 
composites have also become a research hotspot in sensor materials. The addition of metal oxides and polymers to CNT can change their structure and produce quantum tunneling effects, which improves the sensor materials. The electronic transportation capability of the sensor significantly improves the selectivity and sensitivity of the sensor.

This paper reviews the research progress of CNTs and their composites in three kinds of fire detection sensors: $\mathrm{CO}$ gas sensor, temperature sensor and flame sensor. It also introduces the improvement of the sensing characteristics of CNTs for fire detection sensors, which provides a favorable reference for the further application of CNTs in fire detection sensors.

\section{CO GAS SENSOR BASED ON CARBON NANOTUBES}

In the early stage of fire, the main products are the smoke from pyrolysis, including complete combustion products (such as $\mathrm{CO}_{2}$ and $\mathrm{H}_{2} \mathrm{O}$ ) and incomplete combustion products, such as $\mathrm{CO}$, gaseous and liquid hydrocarbons, carbon particles, alcohols, aldehydes, ketones, and other chemical substances. The main components of gas products are $\mathrm{CO}_{2}, \mathrm{CO}$, and water vapor. Because the humidity of air has a great influence on the water vapor content, and the content of $\mathrm{CO}_{2}$ in the air is also high, they are generally not taken as the object of fire detection. Therefore, $\mathrm{CO}$ is regarded as the characteristic gas for early fire detection.

\section{Gas Sensing Mechanism of Sensor}

The traditional semiconductor CO sensor uses the principle of semiconductor conductivity change caused by the adsorption and desorption of gas molecules on the surface of semiconductor materials to detect the gas concentration. However, this kind of sensor has poor gas selectivity and poor stability, so more reliable materials are needed to prepare the sensor. It has been found that the gas sensing mechanism of SWCNTs is due to the formation of three carbon atoms on the surface of SWCNTs $\sigma$ bond, one electron forms delocalized $\pi$ bond between carbon and carbon. When detecting gas, the $\pi$ electron cloud will change, which will lead to the change of sensor conductivity (Yuan et al., 2004). For MWCNTs, MWCNTs can form more winding structure, which makes the sensor have better conductivity (Sayago et al., 2008). The response of gas sensor based on CNTs to gas is greatly dependent on the effective active number of gas adsorbed on the sensor surface (Zhang et al., 2009). When the sensor detects the gas, the gas molecules will be adsorbed on the active sites on the surface of CNTs, and the space charge layer between the electrodes will form a new polarization (Snow, 2005). The sensor can detect the concentration change of the gas to be measured in the environment. However, due to the limitation of their own properties, the adsorption capacity of CNTs is very limited, limited to several strong reducing and oxidizing gases, such as $\mathrm{O}_{2}, \mathrm{NO}_{2}, \mathrm{NH}_{3}, \mathrm{SO}_{2}$, and so on. Many toxic gases and greenhouse gases cannot be adsorbed by intrinsic CNTs, such as $\mathrm{CO}$ and $\mathrm{CO}_{2}$. Therefore, in order to detect more kinds of gases, it is necessary to improve the functionalization of intrinsic CNTs. The main improvement methods include nonmetallic element doping, inorganic metal doping and metal oxide doping. In 2014, Mittal reviewed the interaction between $\mathrm{CO}$ and hydroxylmodified CNTs. This is due to the formation of hydrogen bonds between CNTs and the hydroxyl groups of $\mathrm{CO}$ molecules. The schematic diagram is shown in Figure 1A (Mittal and Kumar, 2014).

\section{Research Status of Carbon Nanotube Based CO Sensors}

In 2000, Kong and others found that CNT has good sensing properties for gas, so there are more and more researches on CNTs and their composites in gas sensors (Kong et al., 2000). In 2008, Wu et al. added $0.1 \%$ CNTs to the $\mathrm{Co}_{3} \mathrm{O}_{4}-\mathrm{SnO}_{2}$ materials, which greatly improved the sensing characteristics of the sensor. The lowest detection limit for $\mathrm{CO}$ concentration was $20 \mathrm{ppm}$, the optimal working temperature was $25^{\circ} \mathrm{C}$, the response value was $23 \mathrm{mV}$, and the relative signal-to-noise ratio was 2.3 (Wu et al., 2008). In 2009, Pearce prepared modified MWCNTs gas sensors by electrophoretic deposition, which improved the speed and reliability of fire gas detectors (Pearce, 2009). In 2010, Leghrib et al. synthesized $\mathrm{SnO}_{2} / \mathrm{CNT}$ gas sensor by precipitation of $\mathrm{SnO}_{2}$ colloidal suspension in CNTs. The sensitivity of $\mathrm{SnO}_{2} / \mathrm{CNT}$ gas sensor to $\mathrm{CO}$ was tested at $150^{\circ} \mathrm{C}$. The results show that $\mathrm{SnO}_{2} /$ CNTs composite has good sensitivity to $2 \mathrm{ppm} \mathrm{CO}$ at this temperature, and the response time is $5 \mathrm{~min}$ (Leghrib et al., 2010). In 2013, Iqbal et al. modified ultrasonic spray with Nano-structure $\mathrm{ZnO}$ by ultrasonic spray pyrolysis method, and conducted gas sensitivity test. The experimental results showed that the sensitivity of the composite to $\mathrm{CO}$ with volume fraction of $100 \mathrm{ppm}$ at $250^{\circ} \mathrm{C}$ was $85 \%$, the response time was $5 \mathrm{~min}$, and

TABLE 1 | Sensing properties of carbon nanotube complexes for CO.

\begin{tabular}{|c|c|c|c|c|}
\hline & $\begin{array}{c}\text { Minimum } \\
\text { detection limit (ppm) }\end{array}$ & Optimum operating temperature $\left({ }^{\circ} \mathrm{C}\right)$ & Response time & Literature \\
\hline $\mathrm{SnO}_{2} / \mathrm{CNT}$ & - & 150 & $5 \mathrm{~min}$ & Leghrib et al. (2010) \\
\hline $\mathrm{Pd}^{2+} / \mathrm{SnO}_{2} / \mathrm{CNT}$ & 5 & 100 & $2 s$ & Hu et al. (2014) \\
\hline SWCNT surface with Au NPs & 1 & 25 & $125 s$ & Choi et al. (2016) \\
\hline Polyaniline-MWCNT & 500 & 25 & $76 \mathrm{~s}$ & Roy et al. (2018) \\
\hline Pt-CNT & - & 100 & $30 \mathrm{~s}$ & Han et al. (2019) \\
\hline $\mathrm{CNT} / \mathrm{CO}_{3} \mathrm{O}_{4}-\mathrm{SnO}_{2}$ & 20 & 25 & - & Wu et al. (2008) \\
\hline
\end{tabular}

CNT, carbon nanotube. 
the recovery time was $20 \mathrm{~min}$ (Iqbal et al., 2013). In 2014, Hu et al. prepared $\mathrm{Pd}^{2+}$ doped $\mathrm{SnO}_{2}$ nanoparticle coated CNTs by sol-gel method. The minimum detection limit of the sensor for $\mathrm{CO}$ is $5 \mathrm{ppm}$, the best working temperature is $100^{\circ} \mathrm{C}$, and the response time is $2 \mathrm{~s}$ (Hu et al., 2014). In 2016, Choi et al. synthesized a network of $\mathrm{Au}$ nanoparticles functionalized SWCNT by impregnation method and self-agglomeration of Au film. The sensor made of this material has high sensitivity and selectivity to low ppm $\mathrm{CO}$ at room temperature, and the detection limit for $\mathrm{CO}$ is as low as $1 \mathrm{ppm}$, achieving good selectivity for $2 \mathrm{ppm} \mathrm{CO}$ for the first time (Choi et al., 2016). In 2018, Loghin et al. used a handwriting technique to create a gas sensor based on CNTs. The sensor has a sensitivity of $0.06 \% \mathrm{ppm}$ for $\mathrm{CO}$ and a measurement range of 5-45 ppm (Loghin et al., 2018). In 2019, Kim et al. fabricated a Pt CNTs flake CO gas sensor by depositing Pt nanoparticles on CNTs. The maximum response time of the sensor is $30 \mathrm{~s}$ and it has good sensitivity to $80 \mathrm{ppm} \mathrm{CO}$ (Han et al., 2019). In 2018, Roy et al. synthesized polyaniline coated MWCNTs and spin coated them on the interdigital electrode of the sensor. The experimental study found that the sensor has good response and repeatability for $500-1,000 \mathrm{ppm} \mathrm{CO}$ at room temperature, with a response time of $76 \mathrm{~s}$ and a recovery time of 210 s (Roy et al., 2018). Table 1 is the sensing properties of carbon nanotube complexes for CO. CNTs gas sensors have attracted much attention due to their low operating temperature and minimum detection limit. Semiconductor CNTs gas sensors doped with oxides have the advantages of both oxide semiconductor gas sensors and CNTs gas sensors, and have the characteristics of high sensitivity, minimum detection limit and low working temperature (Zhang et al., 2013).

\section{FLAME SENSOR BASED ON CARBON NANOTUBES}

In addition to gas and smoke, light will also be produced when the fire happens. The flame has both radiation characteristics and chromaticity characteristics. The flame can radiate in the three parts of the spectrum, namely, ultraviolet, infrared and visible light. Ten percentage of the flame radiates in the ultraviolet light region, and the remaining $90 \%$ of the flame radiates in the infrared and visible light regions (Shekhar et al., 2012; Liu Y. et al., 2017; Gaur et al., 2019), most visible light areas are red and yellow caused by carbon in fire, so infrared and ultraviolet light are generally detected. According to research, CNTs react to radiation, which means that this response can be used to detect various radiation sources, such as those from flames.

\section{Sensing Mechanism of Flame Sensor}

The basic light response mechanism of general photodetectors is to convert the absorbed photons into electrical signals. The light response mechanisms include photoelectric effect, photoconductivity effect, optical gating effect and thermometric effect (Liu P. et al., 2020). CNTs infrared photodetectors are developed on the basis of thermal effect and optical effect. The sensing principle based on thermal effect is that the temperature change caused by light irradiation produces electrical signals (resistance, current or voltage). For the principle of optical effect, excitons are generated through the photon absorption of CNTs, and the electron hole pairs are generated by excitons. It is released by dissociation, thus producing photocurrent or photovoltage in the device (Avouris et al., 2008). Figure 1B is the schematic diagram of the CNT infrared detector (Saleh and Wasan, 2015). When ultraviolet light appears, oxygen molecules on the surface of CNTs are desorbed by the energy of photoinduced plasma polaritons, resulting in a significant decrease in hole concentration, which correspondingly increases the resistance of CNTs. The change of resistance of CNTs under ultraviolet light makes them able to be used for ultraviolet light monitoring (Pyo et al., 2018).

\section{Research Status of Flame Sensors Based on Carbon Nanotubes}

When a fire occurs, the radiation light produced by flame combustion includes ultraviolet light and infrared light. The flame sensor responds to the flame light immediately to judge whether the fire occurs. CNTs are promising materials for the fabrication of high-performance nanooptoelectronic devices due to their unique one-dimensional structure. In 2012, Shao et al. developed a kind of ultraviolet electric detector. The sensor uses CNTs film as coating material. The response of the detector to light frequency of $14 \mathrm{~Hz}$ and wavelength of $365 \mathrm{~nm}$ is about $0.123 \mathrm{~A} / \mathrm{W}$ (Shao et al., 2012). In 2020, Pathak et al. prepared a kind of nanocomposite material based on CNTs and zinc oxide for ultraviolet sensor. The sensitivity of the device to ultraviolet light at $365 \mathrm{~nm}$ is $0.011 \mathrm{~A} / \mathrm{W}$ (Pathak et al., 2020). In 2012, Zeng et al. designed a high-performance infrared detector based on SWCNT array, and its responsivity was $9.87 \times 10^{-5} \mathrm{~A} / \mathrm{W}$ (Zeng et al., 2012). In 2013, Lu et al. self-assembled a heterojunction at the graphene/ MWCNT interface. This nanocomposite material made the detection rate of the infrared detector as high as $1.5 \times$ $10^{7} \mathrm{~cm} \mathrm{~Hz}^{1 / 2} \mathrm{~W}^{-1}$ (Lu et al., 2013). In 2017, Huang et al. transferred the $\mathrm{CNTs} / \mathrm{SiO}_{2}$ structure to the PMMA substrate and designed an infrared detector that has the advantages of fast response speed and high sensitivity (Huang et al., 2017). In 2018, Pavelyev et al. proposed an infrared radiation photodetector based on MWCNT grown on silicon substrate by chemical vapor deposition. The response speed and resistance recovery time of the detector are $3 \mathrm{~min}$ and have obvious hysteresis characteristics (Pavelyev et al., 2018). The traditional flame sensor mainly uses ultraviolet detection and ultraviolet/infrared joint detection. In 2014, Mohanty et al. prepared MWCNTs by chemical vapor deposition method, and designed a functional flame sensor. The response characteristics and sensitivity of the sensor in the transverse and longitudinal direction of the flame were experimentally studied. It has a good working range, and this kind of flame sensor can also be used. Estimation of working distance from flame (Mohanty and Misra, 2014).

\section{TEMPERATURE SENSOR BASED ON CARBON NANOTUBES}

Temperature is one of the most obvious characteristics of a fire. When a fire occurs, a lot of heat is generated by material 
combustion, which makes the surrounding temperature change. The temperature sensor responds to the change of the temperature in the environment immediately to achieve the purpose of fire warning. This section mainly summarizes the research status and sensing principle of temperature sensor based on CNTs.

\section{Sensing Mechanism of Temperature Sensor} CNTs have the characteristics of low power consumption, high sensitivity, high stability, and wide operating temperature range, which can improve the performance of temperature sensors. The temperature measurement of the sensor is not directly expressed, but based on the characteristics of a series of physical phenomena, such as volume expansion, gas pressure change, magnetic susceptibility change, diode junction voltage and resistance exchange, thermocouple generation, and so on. CNTs based sensors use these physical phenomena to detect environmental temperature changes. For example, thermometers can be realized by measuring the thermal expansion of CNTs, because the height of one-dimensional column of continuous liquid in CNTs varies from 50 to $500^{\circ} \mathrm{C}$. In addition, the temperature sensor based on CNTs can also measure the temperature of CNTs caused by thermal interaction. Temperature measurement is realized by changing the conductivity (Pan et al., 2017). Figure 1C shows the SEM image of a temperature sensor based on CNT (Monea et al., 2019).

\section{Research Status of Temperature Sensors Based on Crabon Nanotubes}

CNTs have become an important candidate material for temperature sensors because of their excellent electrical response to temperature changes. In 2011, Karimov et al. designed a thin-film temperature sensor. By depositing a layer of glue and CNTs powder on the paper substrate, the temperature measurement range of the sensor is $20-75^{\circ} \mathrm{C}$, and its sensitivity reaches $-0.24 \% /{ }^{\circ} \mathrm{C}$ (Karimov et al., 2011). In 2013, Ali et al. synthesized the yttrium iron catalyst film on silicon substrate by wet chemical method, and prepared CNTs by chemical deposition method, and made it into a temperature sensor. Its temperature measurement range is $20-150^{\circ} \mathrm{C}$, and the sensitivity is $4.21 \times 10^{-4} /{ }^{\circ} \mathrm{C}$ (Ali and $\mathrm{Hafez}, 2013$ ). In 2015, Karimov et al. proposed a temperature sensor based on $\mathrm{VO}_{2}$ (3-fL) and CNT composite film. The silver electrode was deposited on the glass substrate, and the $\mathrm{VO}_{2}$ (3-fL) and CNTs composite film materials were wrapped on the top of the silver electrode. The temperature measurement range of the sensor was $25-80^{\circ} \mathrm{C}$, and the sensitivity was -(0.9-1.3)\% (Karimov et al., 2015). In 2017, Pan et al. successfully developed an ionization temperature sensor based on CNTs. The sensor has a temperature range of $20-100^{\circ} \mathrm{C}$ and a sensitivity of $4 \times 10^{-2}$ (Pan et al., 2017). In 2017, Song et al. used chemical vapor deposition method to grow vertically aligned $\mathrm{CNT}$ arrays on $\mathrm{SiO}_{2} / \mathrm{Si}$ substrates to prepare a temperature sensor with a temperature measurement range of $20-110^{\circ} \mathrm{C}$ and a sensitivity of $4.74 \mu \mathrm{A} /{ }^{\circ} \mathrm{C}$ (Song et al., 2017). The structure of the sensor is shown in Figure 1D. In the same year, Zuo et al. prepared a CNT-carbon fiber cement-based material, when $0.5 \%$ CNTs were added, the temperature measurement range was $30-60^{\circ} \mathrm{C}$, and the sensitivity was $5.35 \times 10^{-4} /{ }^{\circ} \mathrm{C}$ (Zuo et al., 2017). In 2018, Sarma et al. studied the method of preparing high-efficiency thin-film temperature sensor using layered MWCNT. He prepared a thin-film temperature sensor on $\mathrm{Si}$ substrate by chemical vapor deposition of CNTs film with $\mathrm{Ni}$ as catalyst. The temperature measurement range of the sensor was $22-200^{\circ} \mathrm{C}$, and the sensitivity was $1.03 \times 10^{-3} /{ }^{\circ} \mathrm{C}$ (Sarma and Lee, 2018).

\section{DEVELOPMENT PROSPECT OF CARBON NANOTUBE FIRE DETECTION SENSOR}

With the development of fire detection technology, novel sensing materials have always been an important research field of fire detection sensors, which have an extremely important impact on CO sensors, temperature sensors and flame sensors. The huge aspect ratio and specific surface area of CNTs make them become highly sensitive sensing material layer and efficient sensing channel, but the sensors based on CNTs are still in the primary stage, there are still some problems to be solved: 1) Further research on synthesis methods is needed to improve the uniformity of noble metals and semiconductor metal oxides on the wall of CNTs, so as to improve the response time and sensitivity of the sensor. 2) How to reduce the recovery time of the sensor to achieve the purpose of repeated use. 3) The sensing mechanism of the sensor is not clear, for example, whether the adsorption and desorption model of CO occurs on the surface of CNTs or metal oxides or on the interface between CNTs and metal oxides, so it is necessary to further study the sensor mechanism of the sensor. 4) Improving the sensor's anti-interference ability is of great significance to the improvement of sensor performance. In order to solve these problems, we should optimize the preparation process in the future, make metal oxides and other dopants more evenly distributed on the wall of CNTs; clarify the sensing mechanism of the sensor, explore the electrochemical reaction between $\mathrm{CO}$ gas molecules and which dopants, and use these dopants as the recognition layer of CNTs, which can greatly improve the selectivity of the sensor. Appropriate addition of CNTs, for example, metal oxides, inorganic metals, non-metallic elements, etc., can reduce the recovery time of the sensor. In the future, CNTs can be covered with materials that do not interact with interference sources to reduce interference and enhance the stability of the sensor.

\section{CONCLUSION}

In this paper, the fire detection sensors based on CNTs are reviewed. Firstly, the important role of sensors in the Internet of things is briefly described. The basic structure and preparation methods of CNTs are introduced. The three most commonly used fire detection sensors (CO sensor, temperature sensor and flame sensor) in the fire monitoring system of the Internet of things are analyzed. The current researches of the three kinds of sensors based on CNTs and CNT composites is briefly reviewed. Finally, the problems such as the uniform distribution of dopants, the 
long recovery time and the unclear sensing mechanism of CNT sensors are prospected, improving the anti-interference ability of the sensor, which provide a favorable reference for the further application of CNTs fire detection sensors.

\section{AUTHOR CONTRIBUTIONS}

All authors listed have made a substantial, direct and intellectual contribution to the work, and approved it for publication.

\section{REFERENCES}

Ali, K., and Hafez, M. (2013). Growth and structure of carbon nanotubes based novel catalyst for ultrafast nano-temperature sensor application. Superlattice. Microst. 54, 1-6. doi:10.1016/j.spmi.2012.10.007

Avouris, P., Freitag, M., and Perebeinos, V. (2008). Carbon-nanotube photonics and optoelectronics. Nat. Photonics 2 (6), 341-350. doi:10.1038/nphoton.2008.94

Barcarolle, R., Orecchini, G., Alimenti, F., and Roselli, L. (2013). "Feasibility study of a fully organic, CNT based, harmonic RFID gas sensor," in IEEE international conference on RFID-technologies and applications, November 2012, Nice, France. doi:10.1109/RFID-TA.2012.6404559

Bogue, R. (2013). Sensors for fire detection. Sens. Rev. 33 (2), 99-103. doi:10.1108/ 02602281311299635

Cardenas, J. A., Andrews, J. B., Noyce, S. G., and Franklin, A. D. (2020). Carbon nanotube electronics for IoT sensors. Nano Futures 4, 012001. doi:10.1088/ 2399-1984/ab5f20

Chad, W. R., Bonifas, A. P., Behnaz, A., Zhang, Y. H., Yu, K. J., Cheng, H., et al. (2013). Ultrathin conformal devices for precise and continuous thermal characterization of human skin. Nat. Mater. 12 (10), 938-944. doi:10.1038/NMAT3755

Chen, K., Gao, W., Emaminejad, S., Kiriya, D., Ota, H., Nyein, H. Y. Y., et al. (2016). Printed carbon nanotube electronics and sensor systems. Adv. Mater. 28 (22), 4397-4414. doi:10.1002/adma.201504958

Choi, S.-W., Kim, J., Lee, J.-H., and Byun, Y. T. (2016). Remarkable improvement of CO-sensing performances in single-walled carbon nanotubes due to modification of the conducting channel by functionalization of $\mathrm{Au}$ nanoparticles. Sensor. Actuator. B Chem. 232, 625-632. doi:10.1016/j.snb. 2016.04.035

Ding, C.-J., Zhao, Z.-Y., Xue-hong, Z. H. U., and Yu-bo, F. E. N. G. (2018). Application of neural network in intelligent fire alarm system. Transducer Microsyst. Technol. 37 (1), 154-156. doi:10.13873/J.1000-9787(2018)010154-03

Fonollosa, J., Solórzano, A., and Marco, S. (2018). Chemical sensor systems and associated algorithms for fire detection: a review. Sensors 18 (2), 553. doi:10. 3390/s18020553

Gaur, A., Singh, A., Kumar, A., Kulkarni, K. S., Lala, S., Kapoor, K., et al. (2019). Fire sensing technologies: a review. IEEE Sens. J. 19, 3191-3202. doi:10.1109/ JSEN.2019.2894665

Ge, L., Mu, X., Tian, G., Huang, Q., Ahmed, J., and Hu, Z. (2019). Current applications of gas sensor based on 2-D nanomaterial: a mini review. Front. Chem. 7, 839. doi:10.3389/fchem.2019.00839

Guo, T., Nikolaev, P., Rinzler, A. G., Tomanek, D., Colbert, D. T., and Smalley, R. E. (1995). Self-assembly of tubular fullerenes. J. Phys. Chem. 99 (27), 10694-10697. doi:10.1021/j100027a002

Han, M., Kim, J.-K., Lee, G. S., Kang, S.-W., and Jung, D. (2019). A CO gas sensor based on Pt-loaded carbon nanotube sheets. Jpn. J. Appl. Phys. 58 (SD), SDDE03.1-SDDE03.6. doi:10.7567/1347-4065/ab0497

$\mathrm{Hu}$, Q., Liu, S., and Lian, Y. (2014). Sensors for carbon monoxide based on Pd/ $\mathrm{SnO}_{2} / \mathrm{CNT}$ nanocomposites. Phys. Status Solidi A 211 (12), 2729-2734. doi:10. 1002/pssa.201431392

Huang, Z., Gao, M., Pan, T., Wei, X., Chen, C., and Lin, Y. (2017). Interface engineered carbon nanotubes with $\mathrm{SiO}_{2}$ for flexible infrared detectors. Appl. Surf. Sci. 413, 308-316. doi:10.1016/j.apsusc.2017.04.059

\section{FUNDING}

This work was supported by the National Natural Science Foundation (51874255), Downhole Intelligent Measurement and Control Science and Technology Innovation Team of Southwest Petroleum University (2018CXTD04), the International Science and Technology Cooperation and Exchange Research Project of Sichuan Province (18GJHZ0195), and the International Science and Technology Cooperation Project of Chengdu (2020-GH02-00016-HZ).

Iijima, S. (1991). Helical microtubules of graphitic carbon. Nature 354, 56-58. doi:10.1038/354056a0

Iqbal, M., Yuliarto, B., and Nugraha, N. (2013). Modifications of multi-walled carbon nanotubes on zinc oxide nanostructures for carbon monoxide (CO) gas sensitive layer. Adv. Mater. Res. 789, 12-15. doi:10.4028/www.scientific.net/ AMR.789.12

Jose-Yacaman, M., Miki-Yoshida, M., Rendon, L., and Santiesteban, J. G. (1993). Catalytic growth of carbon microtubules with fullerene structure. Appl. Phys. Lett. 62 (6), 202-204. doi:10.1063/1.109315

Karimov, K. S., Chani, M. T. S., and Khalid, F. A. (2011). Carbon nanotubes film based temperature sensors. Phys. E Low Dimens. Syst. Nanostruct. 43 (9), 1701-1703. doi:10.1016/j.physe.2011.05.025

Karimov, K. S., Mahroof-Tahir, M., Saleem, M., Chani, M. T. S., and Niaz, A. K. (2015). Temperature sensor based on composite film of vanadium complex (VO2(3-fl)) and CNT. J. Semicond. 36 (07), 073004. doi:10.1088/1674-4926/36/ $7 / 073004$

Kong, J., Franklin, N. R., Zhou, C., Chapline, M. G., Peng, S., Cho, K., et al. (2000). Nanotube molecular wires as chemical sensors. Science 287, 622-625. doi:10. 1126/science.287.5453.622

Kwangjae, L., Young-Seok, S., Young, S., Soo, H., Youn-Sung, L., and Chong-Yun, K. (2017). Highly sensitive sensors based on metal-oxide nanocolumns for fire detection. Sensors 17 (2), 303. doi:10.3390/s17020303

Leghrib, R., Pavelko, R., Felten, A., Vasiliev, A., Cané, C., Gràcia, I., et al. (2010). Gas sensors based on multiwall carbon nanotubes decorated with tin oxide nanoclusters. Sensor. Actuator. B Chem. 145 (1), 411-416. doi:10.1016/j.snb. 2009.12.044

Liu, P., Yang, S.-E., Chen, Y., Ma, Y., Liu, S., Fang, X., et al. (2020). Carbon nanotube-based heterostructures for high-performance photodetectors: recent progress and future prospects. Ceram. Int. 46, 19655-19663. doi:10.1016/j. ceramint.2020.05.067

Liu, Y., Pang, L. X., Liang, J., Cheng, M. K., Liang, J. J., Junshu, C., et al. (2017). A compact solid-state UV flame sensing system based on wide-gap ii-vi thin film materials. IEEE Trans. Ind. Electron. 65, 2737. doi:10.1109/TIE.2017.2740842

Loghin, F., Aniello, F., Andreas, A., Salmeron, J. F., Markus, B., Paolo, L., et al. (2018). A handwriting method for low-cost gas sensors. ACS Appl. Mater. Interfaces 10 (40), 34683-34689. doi:10.1021/acsami.8b08050

Lu, R., Christianson, C., Weintrub, B., and Wu, J. Z. (2013). High photoresponse in hybrid graphene-carbon nanotube infrared detectors. ACS Appl. Mater. Interfaces 5 (22), 11703-11707. doi:10.1021/am4033313

Marinov, V. R. (2015). Embedded flexible hybrid electronics for the internet of things. Int. Symp. Microelectron. 2015, 000006-000013. doi:10.4071/isom2015-TP12

Mittal, M., and Kumar, A. (2014). Carbon nanotube (CNT) gas sensors for emissions from fossil fuel burning. Sensor. Actuator. B Chem. 203, 349-362. doi:10.1016/j.snb.2014.05.080

Mohantry, S., and Misra, A. (2014). Carbon nanotube based multifunctional flame sensor. Sensor. Actuator. B Chem. 192, 594-600. doi:10.1016/j.snb.2013.11.019

Monea, B. F., Ionete, E. I., Spiridon, S. I., Ion-Ebrasu, D., and Petre, E. (2019). Carbon nanotubes and carbon nanotube structures used for temperature measurement. Sensors 19 (11), 2464. doi:10.3390/s19112464

Pan, Z., Zhang, Y., Cheng, Z., Tong, J., Chen, Q., Zhang, J., et al. (2017). Sensing properties of a novel temperature sensor based on field assisted thermal emission. Sensors 17, 473. doi:10.3390/s17030473 
Pathak, P., Park, S., and Cho, H. J. (2020). A carbon nanotube-metal oxide hybrid material for visible-Blind flexible UV-sensor. Micromachines (Basel) 11 (3), 368. doi:10.3390/mi11040368

Pavelyev, V. S., Tripathi, N., Mishra, P., Mezhenin, A. V., Kurenkova, Y. G., and Sovetkina, M. A. (2018). CNT-based IR-sensor. J. Phys. Conf. Ser. 1096, 012127. doi:10.1088/1742-6596/1096/1/012127

Pearce, E. R. (2009). Carbon nanotubes as fire gas sensors. PhD thesis. London, UK: Imperial College London. doi:10.25560/5551

Pyo, S., Choi, J., and Kim, J. (2018). A fully transparent, flexible, sensitive, and visible-blind ultraviolet sensor based on carbon nanotube-graphene hybrid. Adv. Electron. Mater. 5, 1800737. doi:10.1002/aelm.201800737

Roy, A., Ray, A., Sadhukhan, P., Naskar, K., Lal, G., Bhar, R., et al. (2018). Polyaniline-multiwalled carbon nanotube (PANI-MWCNT): room temperature resistive carbon monoxide (CO) sensor. Synthetic Metals 245, 182-189. doi:10.1016/j.synthmet.2018.08.024

Saleh, W. R., and Wasan, R. (2015). A carbon nanotubes photoconductive detector for middle and far infrared regions based on porous silicon and a polyamide nylon polymer. Eur. Phys. J. Appl. Phys. 70 (3), 30401. doi:10.1051/epjap/ 2015150121

Sarma, S., and Lee, J. (2018). Developing efficient thin film temperature sensors utilizing layered carbon nanotube films. Sensors 18 (10), 3182. doi:10.3390/ s18103182

Sayago, I., Santos, H., Horillo, M. C., Aleixandre, M., Fernandez, M. J., Terrado, E., et al. (2008). Carbon nanotube networks as gas sensors for $\mathrm{NO}_{2}$ detection. Talanta 77, 758-764. doi:10.1016/j.talanta.2008.07.025

Shao, X., Ma, X., Yu, Y., and Fang, J. (2012). The study of carbon nanotubes as coating films for electrically calibrated detectors. Meas. Sci. Technol. 23 (2), 025106. doi:10.1088/0957-0233/23/2/025106

Sharma, S., Hussain, S., Singh, S., and Islam, S. S. (2014). MWCNT-Conducting polymer composite based ammonia gas sensors: a new approach for complete recovery process. Sensor. Actuator. B Chem. 194, 213-219. doi:10.1016/j.snb.2013.12.050

Shekhar, H., Kumar, S. J., and Rajawat, P. S. (2012). Multi infrared (IR) flame detector for tangential fired boiler. Mobile Commun. Power Eng. 296, 545-548. doi:10.1007/978-3-642-35864-7_84

Shekhar, H., Kumar, S. J., and Rajawat, P. S. (2013). "Multi infrared (IR) flame detector for tangential fired boiler," in AIM: International conference on advances in information technology and mobile communication 2012, Bangalore, India, April 27-28, 2009. Editors V. V. Das and Y. Chaba (Berlin and Heidelberg, Germany: Springer), 545-548.

Snow, E. S. (2005). Chemical detection with a single-walled carbon nanotube capacitor. Science 307 (5717), 1942-1945. doi:10.1126/science.1109128

Song, H., Zhang, Y., and Cao, J. (2017). Sensing mechanism of an ionization as temperature sensor based on a carbon nanotube film. RSC Adv. 7 (84), 53265-53269. doi:10.1039/C7RA09551A

Sundmaeker, H., Guillemin, P., Fries, P., and Woelfflé, S. (2010). Vision and challenges for realising the internet of things. Europe: CERP-IoT. doi:10.2759/ 26127

Takei, K., Yu, Z., Zheng, M., Ota, H., Takahashi, T., and Javey, A. (2014). Highly sensitive electronic whiskers based on patterned carbon nanotube and silver nanoparticle composite films. Proc. Natl. Acad. Sci. U.S.A. 111 (5), 1703-1707. doi:10.1073/pnas.1317920111

Tang, W. (2019). Research progress of flexible gas sensors based on carbon nanomaterials. Bull. Chin. Ceram. Soc. 038 (002), 398-409. doi:CNKI: SUN: GSYT.0.2019-02-01

Wang, J., Yang, Y., Jiao, C., Liang, Y., and Zhang, W. (2018). Research progress of carbon nanotubes in the application of gas sensors. Micronanoelectron. Technol. 55, 239-246. doi:10.13250/j.cnki.wndz.2018.04.003

Wasisto, H. S., Steib, F., Merzsch, S., Waag, A., and Peiner, E. (2014). Vertical silicon nanowire array-patterned microcantilever resonators for enhanced detection of cigarette smoke aerosols. Micro Nano Lett. 9 (10), 676-679. doi: $10.1049 / \mathrm{mnl} .2014 .0249$

Webb, R. C., Bonifas, A. P., Behnaz, A., Zhang, Y., Yu, K. J., Cheng, H., et al. (2013). Ultrathin conformal devices for precise and continuous thermal characterization of human skin. Nat. Mater. 12 (10), 938-944. doi:10.1038/NMAT3755

Wu, R.-J., Wu, J.-G., Yu, M.-R., Tsai, T.-K., and Yeh, C.-T. (2008). Promotive effect of CNT on $\mathrm{Co}_{3} \mathrm{O}_{4}-\mathrm{SnO}_{2}$ in a semiconductor-type $\mathrm{CO}$ sensor working at room temperature. Sensor. Actuator. B Chem. 131 (1), 306-312. doi:10.1016/j.snb.2007.11.033

Xue, G., Ren-Cheng, Z., Xiang-Ying, H., and Xiao-Hua, Z. (2005). Current research and development trends of gas fire detector. Fire Sci. Tech., 735-737. doi:CNKI: SUN: XFKJ.0.2005-06-025.

Yuan, Y., Liu, Z., and Li, X. (2004). Improving SWNT gas sensors by doping atoms. Opt. Mater. Express 000 (010), 7-9. doi:10.3969/j.issn.1002-1841.2004. 10.003

Zeng, Q., Wang, S., Yang, L., Wang, Y., Pei, T., Zhang, Z., et al. (2012). Carbon nanotube arrays based high-performance infrared photodetector [invited]. Opt. Mater. Express 2 (6), 839-848. doi:10.1364/OME.2.000839

Zhang, L., Meng, F., Chen, Y., Liu, J., Sun, Y., Luo, T., et al. (2009). A novel ammonia sensor based on high density, small diameter polypyrrole nanowire arrays. Sensor. Actuator. B Chem. 142 (1), 204-209. doi:10.1016/j.snb.2009.07.042

Zhang, X.-q., Wang, Y.-y., Zhang, K., and He, D.-n. (2013). Research progress of gas sensors based on nanometer materials. Transducer Microsyst. Technol. 32 (5), 1-5, 8. doi:10.3969/j.issn.1000-9787.2013.05.001

Zhu, Z. (2011). Summary of carbon nanotube gas sensor. Sci. Technol. Inf. 000 (022), 119-121. doi:10.3969/j.issn.1001-9960.2011.22.106

Zuo, J., Zhou, H., Yao, W., Wu, D., Liu, X., and Zhang, Y. (2017). Research on the sensing properties of CNT-CF/cement-based materials. Mater. Rev. (22), 125-129. doi:10.11896/j.issn.1005-023X.2017.022.025

Conflict of Interest: The authors declare that the research was conducted in the absence of any commercial or financial relationships that could be construed as a potential conflict of interest.

Copyright (c) 2020 Xiao, Weng, Ge and Huang. This is an open-access article distributed under the terms of the Creative Commons Attribution License (CC $B Y)$. The use, distribution or reproduction in other forums is permitted, provided the original author(s) and the copyright owner(s) are credited and that the original publication in this journal is cited, in accordance with accepted academic practice. No use, distribution or reproduction is permitted which does not comply with these terms. 